University of Nebraska - Lincoln

DigitalCommons@University of Nebraska - Lincoln

\title{
Experimental Assessment of the Impact of Asymptomatic Gas Emboli on the Vessel Wall
}

\author{
Linxia Gu \\ University of Nebraska-Lincoln, gul@fit.edu \\ Eric L. Cutler \\ University of Nebraska-Lincoln
}

Follow this and additional works at: https://digitalcommons.unl.edu/mechengfacpub

Part of the Biomechanical Engineering Commons, Materials Science and Engineering Commons, and the Surgical Procedures, Operative Commons

Gu, Linxia and Cutler, Eric L., "Experimental Assessment of the Impact of Asymptomatic Gas Emboli on the Vessel Wall" (2013). Mechanical \& Materials Engineering Faculty Publications. 93.

https://digitalcommons.unl.edu/mechengfacpub/93

This Article is brought to you for free and open access by the Mechanical \& Materials Engineering, Department of at DigitalCommons@University of Nebraska - Lincoln. It has been accepted for inclusion in Mechanical \& Materials Engineering Faculty Publications by an authorized administrator of DigitalCommons@University of Nebraska Lincoln. 
Published in Journal of Mechanics in Medicine and Biology 13:4 (2013), 1350064 (11 pp); doi: 10.1142/S0219519413500644

Copyright (C) World Scientific Publishing Company. Used by permission.

Submitted August 8, 2012; revised February 6, 2013; accepted February 14, 2013;

published June 4, 2013

\title{
Experimental Assessment of the Impact of Asymptomatic Gas Emboli on the Vessel Wall
}

\author{
Linxia Gu and Eric L. Cutler \\ Department of Mechanical and Materials Engineering, \\ University of Nebraska-Lincoln, Lincoln, NE 68588-0656, USA \\ Corresponding author - 1gu2@unl.edu
}

\begin{abstract}
Quantitative evaluation of shear stress in the vessel wall due to the presence of asymptomatic gas emboli is lacking. The goal of this work was to assess the impact of chronic asymptomatic gas emboli on the risk of atherosclerosis through a custom-built cardiovascular flow simulator. Gas bubbles were created by forced air from a syringe pump. The influences of embolism injection rate, pulse rate, and time-averaged flow rate on the wall mean shear stress were investigated at resting and elevated heart rate conditions. The recorded pressure and volumetric flow rate from 24 experimental settings with four repetitions each were used to calculate the mean wall shear stress (MWSS). A directly inverse relationship between gas embolus rate and MWSS in the vessel, particularly at low vascular flow and diminished pulse rates was subsequently found. This study established a positive correlation between gas bubbles in the bloodstream and diminished MWSS, which implied a potential onset of atherosclerosis.
\end{abstract}

Keywords: gas emboli, artery, shear stress, flow simulator

\section{Introduction}

Asymptomatic gas emboli in the bloodstream are mainly induced as result of a medical procedure or through environmental decompression. ${ }^{1}$ All surgical procedures carry an inherent risk of inducing gas emboli. ${ }^{2,3}$ Whenever the bloodstream is exposed to a gaseous environment, emboli will occur as the atmospheric pressure exceeds the instantaneous blood pressure. The severity of a gas embolus or embolism is commonly considered a function of both patient position and hemodynamic condition. ${ }^{1,4,5}$ Dependent on how the subject is situated the gas bubble will travel to different parts of the body resulting in different clin- 
ical outcomes. For instance, when a patient is operated in left lateral position, it increases the likelihood of trapping emboli in the left ventricle of the heart. ${ }^{5}$ Several other studies have quantified the rate of embolism formation for various specific medical procedures, such as $58 \%$ of craniotomy procedures, $65 \%$ of caesarian section, $30 \%$ of total hip replacement, $24.3 \%$ of venous catheterization, and up to $80 \%$ of neurosurgeries. ${ }^{1,4-6}$

The review of available clinical cases found that a gas infusion rate of $1 \mathrm{~L} /$ min is lethal for humans in less than $2 \mathrm{~min}$ and that a gas embolus of $2 \mathrm{~mL} / \mathrm{kg}$ of body weight would cause tachycardia, hypotension, and raised central venous pressure. ${ }^{7}$ It has also been reported that gas emboli resulting from gynecological surgical procedures generally occur at rates lower than $1 \mathrm{~mL} / \mathrm{kg} / \mathrm{min}^{8}$ and a gas embolus rate of $0.1-0.4 \mathrm{~mL} / \mathrm{kg} / \mathrm{min}$ administered intravenously was non-fatal in humans. However, the upper end of this range would cause decompression sickness like expression. Asymptomatic gas emboli were found to not exceed the rate of $0.2 \mathrm{~mL} / \mathrm{kg} / \mathrm{min}^{8}{ }^{8}$ Based on the averaged body weight of $73.1 \mathrm{~kg}$ in the USA, ${ }^{9}$ the asymptomatic gas embolus rate is less than $15 \mathrm{~mL} / \mathrm{min}$. Under the Spencer gas embolism scale, these would qualify as I-II in classification. ${ }^{10}$

The presence of gas emboli is speculated to reduce the density of blood flow, and thus potentially alter the shear stress acting on the artery wall. It has been well established that a reduction of wall shear stress contributes significantly to the onset of atherosclerosis, which is a common and potentially fatal cardiovascular event. ${ }^{11}$ The endothelium is extremely sensitive to its environment and will adapt accordingly as that environment changes. ${ }^{12}$ As wall shear stress decreases, the cellular lining of the artery will begin to express a different phenotype and produce different chemical signals to change the shape and orientation of endothelial cells, as well as cellular turnover. ${ }^{13}$ These result in the increased permeability of the blood vessel wall, ${ }^{14}$ which allows particles such as cholesterol, calcium, red blood cells, monocytes, and foam cells to accumulate in the vascular intima thus altering the geometry of the blood vessel. This buildup is accelerated by the increased production of adhesion molecules with reduced wall shear stress. ${ }^{15}$ The buildup of these substances injures surrounding tissues, which leads to an additional inflammatory response, furthering the occlusion of blood flow. ${ }^{12}$ In summary, if wall shear stress were to be chronically lowered in a region of the arterial tree, it would subsequently increase the risk of plaque formation. Currently, a time-averaged mean wall shear stress (MWSS) level at 6 dynes $/ \mathrm{cm}^{2}$ or below is considered to be a predictor of the onset of atherogenic behavior. ${ }^{15-17}$

However, the quantitative evaluation on the resulted shear stress within the vessel due to the presence of asymptomatic gas emboli, and thus its link to cardiovascular health, is lacking. In this work, we hypothesized that the presence of gas emboli will reduce the shear stress acting on the artery wall and in turn aggregate the potential risk of atherosclerosis posed by chronic gas emboli. The goal was to test the effect of gas emboli in the carotid and coronary arteries. The selected blood vessels are particularly prone to the onset of atherosclerosis and the consequences of occlusion are very grave. ${ }^{18}$ An in vitro cardiovascular flow simulator was developed to quantify the effect of gas bubbles on the wall mean shear 
stress. The influences of embolism injection rate, pulse rate, and time-averaged flow rate were investigated at resting and elevated heart rate conditions. The recorded pressure and volumetric flow rate are used to calculate the MWSS.

\section{Materials and Methods}

\subsection{In-house cardiovascular flow simulator}

The cardiovascular flow simulator was designed, constructed in house, and refined to produce and monitor the blood flow under various conditions, as illustrated in Figure 1. The pulsatile flow configuration is depicted in solid arrows, and the steadystate flow modification is highlighted in dotted lines with the same test section setups.

A Harvard Apparatus Model 1421 Pulsatile Blood Pump was used to provide the time-dependent flow characteristics of the circulatory system with the use of blood or blood stimulants. A syringe pump was used to create gas flow entering the primary circuit just prior to the test section. By using a $60-\mathrm{mL}$ syringe, a gas flow rate of up to $30 \mathrm{~mL} / \mathrm{min}$ could be achieved. The test section across which the bubbly flow passed was a 0.25 -inch $(6.35-\mathrm{mm})$ inner diameter latex tube fixed on barbed fittings.

A latex tube of 0.25 -inch was used to represent the carotid artery ${ }^{20}$ and coronary artery ${ }^{21,22}$ in the general populace. Due to the practical complications of using actual blood, a mixture of glycerin ( $40 \%$ by volume) with water solvent was used as blood stimulant in this study. This solution is well documented as approximating both the viscosity and density of blood for low frequencies on the order of 100 beats per minute (bpm), moderate temperature, and macroscopic scales. ${ }^{23}$ One gram of cornstarch was subsequently added to the mixture for each liter of liquid. This increased the sonic reflectivity of the medium to make the ultrasound flow meter measurements more reliable and stable.

The Shenitech STUF-300F1G ultrasonic flow meter was utilized to measure and record the volumetric flow of the working fluid. The meter was capable of measuring flow velocities up to $18 \mathrm{~m} / \mathrm{s}$ with an accuracy of $\pm 0.1 \%$ of full range. The 5PSI-D-4V-ASCX differential pressure transducer were situated in a bread-

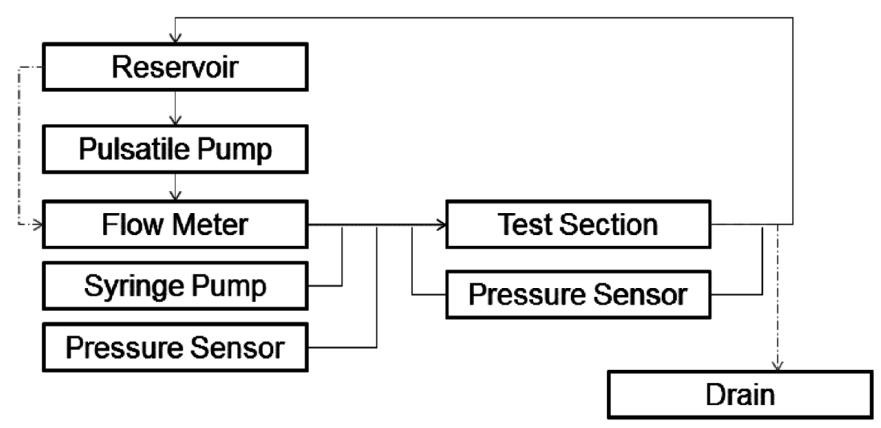

Figure 1. Schematic of the flow simulator. 
board with fluid-filled lines leading to locations upstream and downstream of the test section, and recording the pressure drop across the test section. The sensors have an operating range of $0-5$ psi, a proof pressure of 15 psi, and an accuracy of $\pm 0.1 \%$ of full range.

The data from both of the pressure sensors and the flow meter were subsequently recorded by the National Instruments USB-6009 data acquisition system (DAQ). The experiments were sampled for a duration of $10 \mathrm{~s}$ at a rate of $30 \mathrm{~Hz}$. No aliasing or other unwanted phenomena were ever observed as a result of the sampling rate.

\subsection{Test matrix}

The objective of this study was to assess the effect of gas emboli on wall shear stress under varying parameters (fluid flow, pump frequency, and gas embolism rate). Both the steady and pulsatile experiments were conducted at different volumetric flow rates to simulate the carotid and coronary arteries. Time-averaged volumetric flow rates of $280 \mathrm{~mL} / \mathrm{min}$ for the carotid artery and $130 \mathrm{~mL} /$ min for the coronary artery were used based on the agreement of a number of in vivo measurements. ${ }^{24-28}$ For pulsatile experiments, the tests were further subdivided into resting and elevated experimental conditions. A resting heart beat for a healthy adult was approximated as $70 \mathrm{bpm}$, while an elevated heart rate during or shortly after rigorous activity was averaged as 135 bpm (http://www.americanheart.org). This adjustment was accommodated by the pump. Furthermore, four progressive gas embolus rates were examined under each particular flow and pulse setting tests. These four values were 0 (baseline), 5, 10, and $15 \mathrm{~mL} / \mathrm{min}$ spanning the range of asymptomatic gas emboli injection rates. ${ }^{8,9}$ In terms of the Spencer scale, these emboli would be characterized on the order of I-II. ${ }^{10}$ The hierarchical testing setup is provided in a matrix form in Table 1.

There were 24 experimental settings in total and each test setup was repeated four times. MATLAB was used to process the large amounts of data generated. The Savitzky-Golay filter was utilized to minimize the noise magnification

Table 1. Test configuration matrix.

\begin{tabular}{|c|c|c|c|c|c|}
\hline \multirow{2}{*}{$\begin{array}{l}\text { Characteristic } \\
\text { flow } \\
\text { Volumetric } \\
\text { fluid flow }\end{array}$} & \multicolumn{2}{|c|}{ Steady } & \multicolumn{3}{|c|}{ Pulsatile } \\
\hline & $\begin{array}{c}\text { Carotid } \\
(280 \mathrm{~mL} / \mathrm{min})\end{array}$ & $\begin{array}{l}\text { Coronary } \\
(130 \mathrm{~mL} / \mathrm{min})\end{array}$ & \multicolumn{2}{|c|}{$\begin{array}{c}\text { Carotid } \\
(280 \mathrm{~mL} / \mathrm{min})\end{array}$} & $\begin{array}{l}\text { Coronary } \\
\text { (130 mL/min) }\end{array}$ \\
\hline Frequency & $\mathrm{N} / \mathrm{A}$ & $\mathrm{N} / \mathrm{A}$ & $\begin{array}{l}\text { Resting } \\
70 \mathrm{bpm}\end{array}$ & $\begin{array}{l}\text { Exercise } \\
135 \mathrm{bpm}\end{array}$ & $\begin{array}{ll}\text { Resting } & \text { Exercise } \\
70 \mathrm{bpm} & 135 \mathrm{bpm}\end{array}$ \\
\hline $\begin{array}{l}\text { Embolism } \\
\text { injection rat } \\
\text { (mL/min) }\end{array}$ & ate 051015 & 051015 & 051015 & 051015 & $\begin{array}{lllllll}0 & 510 & 150 & 5 & 10 & 15\end{array}$ \\
\hline
\end{tabular}


through a local polynomial regression method. The cutoff frequency was set to 3 $\mathrm{Hz}$, which did not result in any aliasing or unwanted effects.

Before conducting either set of tests, the simulator was circulated and cleaned using an aqueous vinegar solution poured into the reservoir. This mildly acidic mixture provided a gentle non-caustic cleaning agent to remove any debris or residues from previous experiments. The system was subsequently drained and refilled with water. This second circulation cleaning with water was to remove any residual vinegar, thus helping to ensure that the test fluid is uncontaminated. Before every test, the settings of the pulsatile and syringe pumps would be adjusted to the desired values. Both pumps would then be activated and allowed a brief period to settle into steady state operation.

\subsection{Properties of multiphase mixture}

The density of each constituent of the mixture is weighted by the volumetric percentage, a value known as the void fraction and denoted by $\alpha_{k}$. This value is used as a coefficient for the density in the summation to calculate apparent density of the mixture, ${ }^{29}$ as expressed below:

$$
\alpha_{k}=\frac{V_{k}}{V} \quad \mathcal{E} \quad \rho=\sum_{k=1}^{N} \alpha_{k} \rho_{k}
$$

It should be noted that this approach to calculating density assumes that the mixture is reasonably well mixed and does not have any significant discontinuities, as demonstrated in our tests. Although there are several methods for calculating multiphase mixture viscosity the equation shown below was a consistent presence in the relevant literature ${ }^{30,31}$ :

$$
\ln \mu=\sum_{k=1}^{N} \alpha_{k} \ln \mu_{k}
$$

The material properties of each fluid involved in this test, displayed in Table 2,32 were used to calculate the density and viscosity for each of the flow rate pairings (blood simulant and embolism) according to the equations outlined above (Table 3). It is clear that a slower flow rate as well as a larger amount of gas embolism led to the reduced density and viscosity of the multiphase mixture.

Table 2. Properties of experimental fluids at standard temperature and pressure.

\begin{tabular}{lccc}
\hline Fluid & Glycerin & Water & Air \\
\hline Density & $1260 \mathrm{~kg} / \mathrm{m}^{3}$ & $998 \mathrm{~kg} / \mathrm{m}^{3}$ & $1.2 \mathrm{~kg} / \mathrm{m}^{3}$ \\
Viscosity & $1.2 \mathrm{~Pa} \cdot \mathrm{S}$ & $8.94 * 10^{-4} \mathrm{~Pa} \cdot \mathrm{S}$ & $18.12 * 10^{-6} \mathrm{~Pa} \cdot \mathrm{S}$ \\
\hline
\end{tabular}


Table 3. Fluid properties for various flow pairings.

\begin{tabular}{lcccccc}
\hline & \multicolumn{6}{c}{ Gas infusion rate (mL/min) } \\
& & 0 & 5 & 10 & 15 & \\
\hline Time-averaged blood & 130 & 1102.8 & 1062 & 1024.114 & 988.8414 & Density \\
simulant flow (mL/min) & 280 & 1102.8 & 1083.474 & 1064.814 & 1046.786 & $\left(\mathrm{~kg} / \mathrm{m}^{3}\right)$ \\
Time-averaged blood & 130 & 0.01594 & 0.0124 & 0.009821 & 0.007905 & Viscosity \\
simulant flow (mL/min) & 280 & 0.01594 & 0.014152 & 0.012617 & 0.011292 & $(\mathrm{~Pa} \cdot \mathrm{s})$ \\
\hline
\end{tabular}

\section{Results}

\subsection{Evaluation of the wall shear stress}

The conservation of momentum equations along axial direction was used to derive the wall shear stress. The horizontally mounted axisymmetric test setup with fully developed fluid flow eliminates the convective derivatives term and simplifies the Laplacian operator to radial terms only. The integral of the shear stressand fluid velocity were approximately by the mean velocity of the flow, $\bar{\mu}$, and the shear stress at the vessel wall, $\tau_{\omega}$. This led to the wall shear stress derived as:

$$
\rho \frac{\partial \bar{\mu}}{\partial t}=\frac{d p}{d z}+\frac{4 \tau_{\omega}}{D} \rightarrow \tau_{\omega}=\frac{D}{4}\left(\rho \frac{\partial \bar{\mu}}{\partial t}+\frac{d p}{d z}\right)
$$

where $\rho$ refers to density, $t$ to time, and $p$ to pressure. One of the other key assumptions in using the above equation was that the flow was fully developed. To verify this assumption, the length of the entrance region $L_{e^{\prime}}$ which tied with the Reynolds number of the flow, was used to guide the test setup.

The fluid density and viscosity in Table 3 were used to calculate the Reynolds number of the time-averaged flow leading up to the test section, as listed in Table 4. The Reynolds number is proportional to the diameter of the tube as well as the flow mean velocity. It is apparent that the obtained Reynolds numbers were much lower than any threshold for onset of turbulent flow. Thus, the laminar form of the pipe entrance length equation $L_{e}=0.06 * D * \operatorname{Re}$ was used to calculate the entrance length for various setup. ${ }^{33}$ Results showed that a minimal entrance length of 1.378 inches $(3.48 \mathrm{~cm})$ was required for the test section having a

Table 4. Fluid properties for various flow pairings.

\begin{tabular}{lcccccc}
\hline & \multicolumn{6}{c}{ Gas infusion rate $(\mathrm{mL} / \mathrm{min})$} \\
& & 0 & 5 & 10 & 15 & \\
\hline Time-averaged blood & 130 & 30.06 & 38.64 & 48.79 & 60.62 & \multirow{2}{*}{$\operatorname{Re}$} \\
simulant flow (mL/min) & 280 & 64.74 & 72.92 & 81.79 & 91.39 & \\
Time-averaged blood & 130 & 1.15 & 1.47 & 1.86 & 2.31 & Entrance \\
simulant flow (mL/min) & 280 & 2.47 & 2.78 & 3.12 & 3.48 & length (cm) \\
\hline
\end{tabular}


fully developed flow condition. In our simulator, the length of uniform tube leading up to the test section was measured as 6 inches in length. Thus, it is safe to assume that the flow in the test section is fully developed.

\subsection{Steady flow}

The average MWSS was calculated for the eight tests specified in the test matrix (Table 1). Figure 2 demonstrated that the embolism rate has an inverse relationship with the MWSS at certain volumetric flow rate. The linear correlation between embolism rate and the MWSS was apparent with correlation factors of 0.9988 for the carotid flow and 0.9958 for the coronary flow condition. This indicated that the relationship between MWSS and embolism rate is linear for hydrostatic flows, regardless the volumetric flow rate. The above linear relation has very similar downward slopes with approximate $4.2 \%$ difference, where the slope is -0.1518 for the carotid flow and -0.1584 for the coronary flow. In addition, it appears that standard error increases with increased embolism presence.

It can also be noted that a smaller fluid flow rate reduced wall shear stress, as expected. It has been well established that a reduction of wall shear stress contributes significantly to the onset of atherosclerosis, which is a common and potentially fatal cardiovascular event. ${ }^{11}$ A time-averaged MWSS threshold of 6 dynes/ $\mathrm{cm}^{2}$ was considered in this work to indicate the potential onset of atherogenic behavior. ${ }^{15-17}$ It is clear that the MWSS for all the coronary flow conditions is below this threshold value and implied that the presence of gas emboli significantly increased risk of plaque formation in coronary artery. Although the steady flow does not mimic the physiological conditions, it could provide a baseline dataset to examine the effects of pulsatility on the severity of gas emboli.

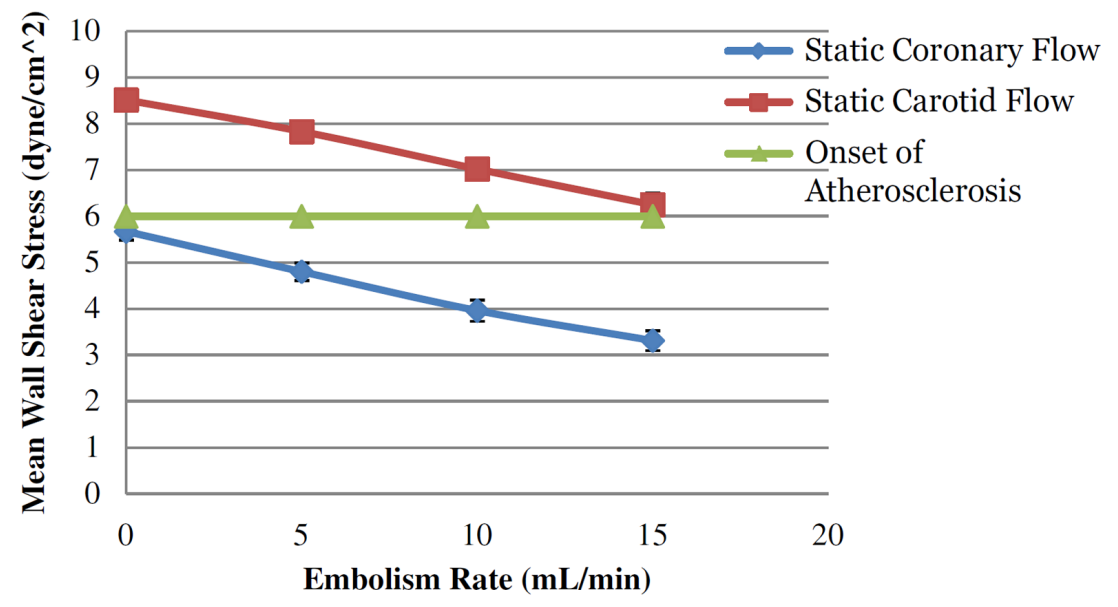

Figure 2. MWSS versus embolism rate for the steady-state flow. 


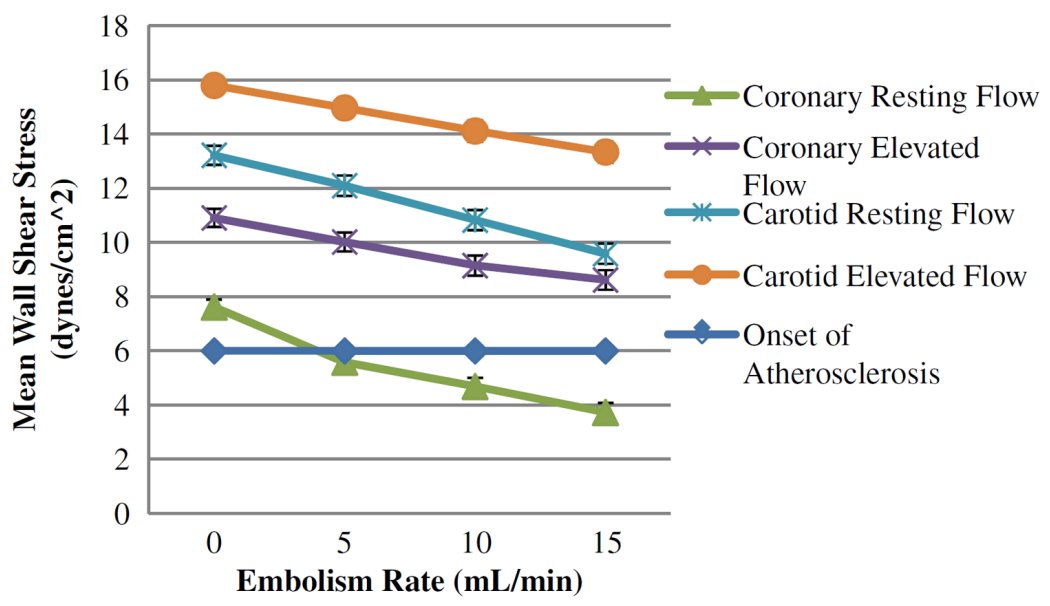

Figure 3. Pulsatile MWSS versus embolism rate.

\subsection{Pulsatile flow}

For the pulsatile flow, the persistent decrease in MWSS with embolism rate is also presented (Figure 3). Although the MWSS does decrease with embolism rate for all of the configurations, some nonlinearity appears especially close to the 10$15 \mathrm{~mL} / \mathrm{min}$ region. All of the mean wall shear stresses increase in a consistent manner with increased heart rate. It would appear that the coronary cardiovascular flow setting consistently produces lower MWSS, especially with low pulsatility. It should also be noted that the resting heart rate with coronary flow was the only series to dip below the threshold of 6 dynes $/ \mathrm{cm}^{2}$. As previously stated, this shear stress regime is closely associated with the risk of atherosclerosis formation.

The standard error of MWSS increased consistently with embolism rate. Moreover, both MWSS and standard error increased as a function of increased fluid flow rate. Higher heart rates were observed to generally increase both MWSS and standard error as well. It should be noted that the stand error levels were significantly higher for pulsatile results than for steady-state, regardless of peripheral test settings. The maximum standard error observed for the hydrostatic tests was 0.25 dynes $/ \mathrm{cm}^{2}$, while it was 0.39 dynes $/ \mathrm{cm}^{2}$ for pulsatile experiments.

\section{Discussions and Conclusions}

This study was undertaken to investigate the effects of chronic asymptomatic gas emboli on MWSS; it is well recognized that the reduced wall shear stress is a significant contributor to the formation of atherosclerosis. A variety of cardiovascular circumstances, namely varying fluid flow rates and pulse frequencies, were investigated and are summarized as the following.

The MWSS had an inversely proportional relationship with gas bubble infusion rate and a directly proportional relationship with circulatory volume flow and heart rate. This indicates that an increased volume of asymptomatic gas em- 
boli in the bloodstream would most likely decrease local arterial MWSS, particularly in regions with low volumetric flow or diminished pulse.

This work treated the bubbly flow as a well-mixed continuum. The flow created by the circulatory simulator remained well within the bubbly regime throughout testing, which is typified by bubbles dispersed in the liquid. When shear forces are dominant, the bubbles tend to disperse uniformly throughout the lumen. ${ }^{34}$ This best describes the properties of asymptomatic gas emboli. ${ }^{35}$ In fact, the transition between flow regimes is largely governed by the void fraction (defined earlier as $\left.\alpha_{k}\right)$. With a maximum void fraction of $11.5 \%(15 \mathrm{~mL} / \mathrm{min}$ maximum gas infusion and $130 \mathrm{~mL} / \mathrm{min}$ minimum blood simulant flow), the presence of the fluid is not nearly enough to create significant coalescence or occlusion of the lumen. ${ }^{35,36}$ In the actual experimental testing, this bubbly flow/continuum body was visually confirmed. The bubbles produced by the test apparatus were small and evenly distributed longitudinally with a very slight bias toward the top of the tube. Also, significant jumps were not seen in the wall shear stress data. It would be necessary to perform similar tests on actual biological specimens through organ culture and establish a more direct link between gas emboli and atherosclerotic onset.

One situational instance was found (in the coronary artery at a resting heart rate with gas embolus rate in excess of $5 \mathrm{~mL} / \mathrm{min}$ ) of a MWSS low enough to induce the onset of atherosclerosis. But this evidence is certainly not sufficient to demonstrate a real-world medical issue with any certainty. Rather, this study laid the ground work for future investigations into the effects of gas emboli on endothelial function. The research was able to clearly establish a positive link between bubbles in the bloodstream and decreased MWSS. It was also able to identify peripheral circumstances that would exacerbate this fluid mechanical response.

Acknowledgments - This study was supported in part by the NASA Nebraska Space Grant and National Science Foundation under Grant No. 0926880.

\section{References}

1. Muth CMS, Eric S, Gas embolism, N Engl J Med 342(7):476-482, 2000.

2. Barak M, Katz Y, Microbubbles: Pathophysiology and clinical implications, Chest 128(4):2918-2932, 2005.

3. Van Hulst RA, Klein J, Lachmann B, Gas embolism: Pathophysiology and treatment, Clin Physiol Funct Imaging 23(5):237-246, 2003.

4. Mathieu D, Handbook on Hyperbaric Medicine, Springer, Amsterdam, 2006.

5. Souders J, Pulmonary air embolism, J Clin Monit Comput 16:375-383, 2000.

6. Tillie-Lebond IM, Marquette $\mathrm{CH}$, Perez T, Scherpereel A, Zanetti C, Tonnel A, RemyJardin M, Pulmonary embolism in patients with unexplained exacerbation of chronic obstructive pulmonary disease: Prevalence and risk factors, Ann Intern Med 144(6): 390396, 2006. Experimental Assessment of the Impact of Asymptomatic Gas Emboli on the Vessel Wall 1350064-9

7. Pescod D, Developing Anaesthesia: Guidelines for Anaesthesia in Developing Countries, Retrieved from http://www.developinganaesthesia.org/uploads/1/1/9/5/11950500/ developinganaesthesia textbook1.6.pdf , 2007. 
8. Weissman AK, Kol S, Peretz BA, Gas embolism in obstetrics and gynecology. A review, J Reprod Med 41(2):103-111, 1996.

9. Ogden CL, Fryar CD, Carroll MD, Flegal KM, Mean body weight, height, and body mass index, United States 1960-2002, Adv Data Vital Health Stat 347:1-20, 2004.

10. Wessel JH, III, Conkin J, Description of the NASA hypobaric decompression sickness database 1982-1998, Aviat Space Env Med 79(3):48, 2008.

11. Gnasso A, Irace C, Carallo C, De Franceschi MS, Motti C, Mattioli PL, Pujia A, In vivo association between low wall shear stress and plaque in subjects with asymmetrical carotid atherosclerosis, Stroke 28:993-998, 1997.

12. Pedersen EM, Oyre S, Agerbaek M, Kristensen IB, Ringgaard S, Boesiger P, Paaske WP, Distribution of early atherosclerotic lesions in the human abdominal aorta correlates with wall shear stresses measured in vivo, Eur J Vasc Endovasc Surg 18:328-333, 1999.

13. Elhadj S, Chronic shear stress effects on endothelial cell response, Virginia Polytechnic Institute and State University, Blacksburg, 2001.

14. Gibson CM, Diaz L, Kandarpa K, Sacks FM, Pasternak RC, Sandor T, Feldman C, Stone $\mathrm{PH}$, Relation of vessel wall shear stress to atherosclerosis progression in human coronary arteries, Arterioscler Thromb Vasc Biol 13:310-315, 1993.

15. Reneman RS, Arts T, Hoeks AP, Wall shear stress - An important determinant of endothelial cell function andstructure - in the arterial system in vivo, J Vasc Res 43:251-269, 2006.

16. Cunningham KS, Gotlieb AI, The role of shear stress in the pathogenesis of atherosclerosis, Lab Invest 85:9-23, 2005.

17. Bonert M, Leask RL, Butany J, Ethier CR, Myers JG, Johnston KW, Ojha M, The relationship between wall shear stress distributions and intimal thickening in the human abdominal aorta, BioMed Eng OnLine 2:18, doi: 10.1186/1475-925X-2-18, 2003.

18. Zarins CK, Giddens DP, Bharadvaj BK, Sottiurai VS, Mabon RF, Glagov S, Carotid bifurcation atherosclerosis. Quantitative correlation of plaque localization with flow velocity profiles and wall shear stress, Circ Res 53:502-514, 1983.

19. Coats AJS, Shewan LG, Statement on authorship and publishing ethics in the International Journal of Cardiology, Int J Cardiol 153(3):239-240, 2011.

20. Krejza J, Arkuszewski M, Kasner SE, Weigele J, Ustymowicz A, Hurst RW, Cucchiara BL, Messe SR, Carotid artery diameter in men and women and the relation to body and neck size, Stroke 37:1103-1105, 2006.

21. Funabashi N, Kobayashi Y, Perlroth M, Rubin GD, Coronary artery: Quantitative evaluation of normal diameter determined with electron-beam CT compared with cine coronary angiographyinitial experience, Radiology 226(1):263-271, 2002.

22. Sheifer SE, Canos MR, Weinfurt KP, Arora UK, Mendelsohn FO, Gersh BJ, Weissman $\mathrm{NJ}$, Sex differences in coronary artery size assessed by intravascular ultrasound, $A m$ Heart J 139(4):649-653, 2000.

23. Deutsch S, Tarbell JM, Manning KB, Rosenberg G, Fontaine AA, Experimental fluid mechanics of pulsatile artificial blood pumps, Annu Rev Fluid Mech 38:65-86, 2006.

24. Ford MD, Alperin N, Lee SH, Holdsworth DW, Steinman DA, Characterization of volumetric flow rate waveforms in the normal internal carotid and vertebral arteries, Physiol Meas 26:477-488, 2005.

25. Ho SS, Chan YL, Yeung DK, Metreweli C, Blood flow volume quantification of cerebral ischemia: Comparison of three noninvasive imaging techniques of carotid and vertebral arteries, Am J Roentgenol 178:551-556, 2002. L. Gu E E. L. Cutler 1350064-10 
26. Schöning M, Walter J, Scheel P, Estimation of cerebral blood flow through color duplex sonography of the carotid and vertebral arteries in healthy adults, Stroke 25:17-22, 1994.

27. Ganz W, Tamura K, Harold SM, Donoso R, Yoshida S, Swan HJC, Measurement of coronary sinus blood flow by continuous thermodilution in man, Circulation 44:181-195, 1971.

28. Aarnoudse W, Van't Veer M, Pijls NH, Ter Woorst J, Vercauteren S, Tonino P, Geven M, Rutten M, van Hagen E, de Bruyne B, van de Vosse F, Direct volumetric blood flow measurement in coronary arteries by thermodilution, J Am Coll Cardiol 50(24): 22942304, 2007.

29. Ishii M, Hibiki T, Thermo-Fluid Dynamics of Two-Phase Flow, 2nd edn. Springer, New York, 2011.

30. Bloomfield VA, Dewan RK, Viscosity of liquid mixtures, J Phys Chem 75(20):3113- 3119, 1971.

31. Saksena MP et al., Viscosity of binary liquid mixtures, J Phys Chem 8:2376-2381, 1975.

32. White FM, Viscous Fluid Flow, 3rd edn. McGraw-Hill, Boston, 2005.

33. Clift R, Grace JR, Weber ME, Bubbles, Drops, and Particles, Academic Press, New York, 1978.

34. Thome JR, Two-phase flow patterns, In Engineering Data Book III, Wolverine Tube, Huntsville, Retrieved from http://www.wlv.com/products/databook/db3/data/ db3ch12.pdf , 2007.

35. Balasubramaniam R, Ramé E, Kizito J, Kassemi M, Two phase dlow modeling: Summary of flow regimes and pressure drop correlations in reduced and partial gravity, NASA Contractor Report, Cleveland, p. 74, 2006.

36. Yeoh GH, Tu J, Computational Techniques for Multiphase Flows, Elsevier, Oxford, 2009. 